\title{
STROKE IN YOUNG AGE - STUDY OF 50 CASES
}

\author{
MD. TITU MIAH ${ }^{1}$, A. K. M. AMINUL HOQUE ${ }^{2}$, BINOY KRISHNA TARAFDER ${ }^{3}$, SYED MOHAMMAD \\ ALI ROMEL $^{4}$, MD. KAMRUL HASSAN ${ }^{4}$
}

\begin{abstract}
:
Stroke in young age is relatively uncommon but has serious impact on the affected family as well as society. The causes are more diversed and differ as compared to the elderly. Overall prognosis is better than elderly but there is still significant morbidity and mortality. We studied consecutive 50 stroke patients between the age of 15-45 admitted in Mymensingh Medical College Hospital. The objective of this study was to evaluate the aetiological pattern, associated risk factors and inpatient outcome. Mean age of the patients was $35.8 \pm 7.39 \mathrm{SD}$ (years), female male ratio was 1 : 1.27. Infarction was found in 60\% cases. Haemorrhage was in $40 \%$ cases. Dyslipidaemia was mostly associated risk factor in both infarction (83.3\%) and in haemorrhage (75\%). In 74\% cases aetiology could not be identified. High prevalence of dyslipidemia as associated risk factor may indicate premature atherosclerosis. Overall in-patient mortality was $12 \%$. Mortality in haemorrhagic strokes is higher.
\end{abstract}

\section{Introduction:}

Stroke is the leading cause of adult disability and is the second commonest cause of death worldwide. ${ }^{1}$ The disorder usually occurs in middle aged and elderly. It is relatively uncommon in young adults but the effect may be devastating for the affected individual and their families. The incidence of stroke in young adults is variable among different studies and surveys. Like in older adults, stroke in younger adults is typically categorized as primarily ischemic or hemorrhagic. Transient ischaemic attacks are rare in young age. Haemorrhagic strokes are relatively more common. The cause can be found in $55-93 \%$ young patients ${ }^{2-4}$ and are more heterogenous and differ dramatically compared to the elderly and also as in infants and children. Ischemic etiologies include cardioembolic, atherosclerotic disease, and nonatherosclerotic cerebral vasculopathies. Hemorrhagic strokes include subarachnoid and intracerebral types. Up to $45 \%$ of strokes in young adults are due to spontaneous intracerebral hemorrhage. Vascular malformations, aneurysms, hypertension, illicit drug use, coagulation abnormality, eclampsia are the main causes. In cases of subarachnoid haemorrhage, ruptured aneurysm, arteriovenous malformation, venous angioma are responsible. ${ }^{5}$ Of particular note in young adults are stroke causes such as haematologic disorders, substance abuse, trauma, dissections, oral contraceptive use, pregnancy and postpartum states, and migraine. Stroke that remain without a definite cause even after extensive work up are classified as cryptogenic. These constitute about $30-40 \%$ of all strokes. Clinical manifestations and management are usually similar to older population with some aspects of treatment are given when specific causes are found. Overall prognosis is better than older patients despite significant morbidity, dependency and mortality.

\section{Materials and Methods:}

This is an observational study done from January to June, 2008 in Mymensingh Medical College Hospital which is a tertiary referral centre for the districts of greater Mymensingh. We studied consecutive 50 cases of stroke patients aged between 15 and 45 years. Detailed history was taken and all patients were examined thoroughly to elicit the aetiological and risk factors. All were investigated with routine blood count, urine examination, blood sugar, Lipid profile, serum creatinine, ECG, Chest $\mathrm{X}$-ray and CT scan of brain. Further investigations were done according to the clinical and laboratory findings. Treatment was given accordingly and inpatient outcome were observed.

1. Junior Consultant, Medicine Unit -4, Mymensingh Medical College Hospital

2. Associate Professor, Medicine Unit -4, Mymensingh Medical College Hospital

3. Assistant Registrar, Medicine Unit -4, Mymensingh Medical College Hospital

4. IMO, Medicine Unit -4, Mymensingh Medical College Hospital 


\section{Results:}

50 cases of stroke patients involved in this study aged between 15 to 45 years with a mean age of $35.8(+/$ 7.39SD) years and male, female ratio was 1: 1.27.
Mortality rate was $12 \%$. Table-I describes variation of stroke patients in male, female distribution and sum of each case with percentage.

Table-I

Type of stroke with gender variation

\begin{tabular}{lccc}
\hline Type & Male & Female & Total \\
\hline Infarction & $17(34 \%)$ & $13(26 \%)$ & $30(60 \%)$ \\
Intracerebral haemorrhage & $10(20 \%)$ & $08(16 \%)$ & $18(36 \%)$ \\
Subarachnoid haemorrhage & $01(2 \%)$ & $01(2 \%)$ & $02(4 \%)$ \\
\hline Total & $28(56 \%)$ & $22(44 \%)$ & $50(100 \%)$ \\
\hline
\end{tabular}

Table-II

Stroke patients with infarction and haemorrhage in different age groups.

\begin{tabular}{lccc}
\hline Age group (years) & Infarction $(\%)$ & Haemorrhage $(\%)$ & Total (\%) \\
\hline $15-20$ & $0(0)$ & $1(2)$ & $1(2)$ \\
$21-25$ & $3(6)$ & $2(4)$ & $5(10)$ \\
$26-30$ & $5(10)$ & $1(2)$ & $6(12)$ \\
$31-35$ & $7(14)$ & $9(18)$ & $16(32)$ \\
$36-40$ & $7(14)$ & $2(4)$ & $9(18)$ \\
$41-45$ & $8(16)$ & $5(10)$ & $13(26)$ \\
\hline
\end{tabular}

Table-II, patients are distributed in 6 age groups. In each group, patients are divided into infarction and haemorrhagic types.

Table-III describes different risk factors in 30 patients with infarctive stroke. Dyslipidemia is associated with highest $83.3 \%$ patient. $69.2 \%$ female patients have taken OCP.

Table-III

Different risk factors of infarctive stroke with male, female distribution.

\begin{tabular}{lccc}
\hline Risk factors & Male & Female & Total \\
\hline Dyslipidemia & $14(46.7 \%)$ & $11(36.6 \%)$ & $25(83.3 \%)$ \\
Hypertension & $5(16.7 \%)$ & $5(16.7 \%)$ & $10(33.4 \%)$ \\
Smoking & $8(26.7 \%)$ & $1(3.3 \%)$ & $9(30 \%)$ \\
OCP & & $9(69.2 \%)^{*}$ & \\
Family H/O stroke & $5(16.7 \%)$ & $2(6.6 \%)$ & $7(23.3 \%)$ \\
Family H/O Hypertension & $5(16.7 \%)$ & $1(3.3 \%)$ & $6(20 \%)$ \\
Family H/O IHD & $2(6.7 \%)$ & $19(3.3 \%)$ & $3(10 \%)$ \\
DM & $2(6.7 \%)$ & $0(0 \%)$ & $2(6.7 \%)$ \\
IHD & $1(3.3 \%)$ & $1(3.3 \%)$ & $2(6.7 \%)$ \\
Alcohol & $1(3.3 \%)$ & $0(0 \%)$ & $1(3.3 \%)$ \\
\hline
\end{tabular}


Table-IV , lilpid profile of patients are described. Highest $73.2 \%$ patients have high level of LDL.

Table-IV

Lipid profile of patients with infarctive stroke.

\begin{tabular}{lccc}
\hline Lipid profile & Male & Female & Total \\
\hline High LDL $(\geq 100 \mathrm{mg} / \mathrm{dl})$ & $18(59.9 \%)$ & $4(13.3 \%)$ & $22(73.2 \%)$ \\
Low HDL $(£ 35 \mathrm{mg} / \mathrm{dl})$ & $14(46.6 \%)$ & $4(13.3 \%)$ & $18(59.9 \%)$ \\
High Cholesterol $(>200 \mathrm{mg} / \mathrm{dl})$ & $8(26.6 \%)$ & $2(6.6 \%)$ & $10(33.2 \%)$ \\
Triglyceride $(>150 \mathrm{mg} / \mathrm{dl})$ & $4(13.3 \%)$ & $4(13.3 \%)$ & $8(26.7 \%)$ \\
\hline
\end{tabular}

Table-V shows patients with haemorrhagic stroke, 20 in numbers, with different risk factors. Highest $75 \%$ patients have Dyslipidemia.

\section{Table-V}

Different risk factors of haemorrhagic stroke with male, female distribution.

\begin{tabular}{lccc}
\hline Risk factors & Male & Female & Total \\
\hline Dyslipidemia & $8(40 \%)$ & $7(35 \%)$ & $15(75 \%)$ \\
Hypertension & $7(35 \%)$ & $5(25 \%)$ & $10(60 \%)$ \\
Family H/O Hypertension & $7(35 \%)$ & $3(15 \%)$ & $10(50 \%)$ \\
Smoking & $9(45 \%)$ & $1(5 \%)$ & $10(50 \%)$ \\
Family H/O stroke & $9(45 \%)$ & $0(0 \%)$ & $9(45 \%)$ \\
DM & $3(15 \%)$ & $1(5 \%)$ & $4(20 \%)$ \\
Family H/O IHD & $3(15 \%)$ & $1(5 \%)$ & $4(20 \%)$ \\
OCP & & $3(33.3 \%)^{*}$ & \\
IHD & $1(5 \%)$ & $0(0 \%)$ & $1(5 \%)$ \\
Alcohol & $1(5 \%)$ & $0(0 \%)$ & $1(5 \%)$ \\
\hline
\end{tabular}

Table-VI, highest 70\% patients have high lipid level.

Table-VI

Lipid profile of patients with haemorrhagic stroke.

\begin{tabular}{lccc}
\hline Lipid profile & Male & Female & Total \\
\hline High LDL $\left({ }^{3} 100 \mathrm{mg} / \mathrm{dl}\right)$ & $8(40 \%)$ & $6(30 \%)$ & $14(70 \%)$ \\
Low HDL $(£ 35 \mathrm{mg} / \mathrm{dl})$ & $8(40 \%)$ & $4(20 \%)$ & $12(60 \%)$ \\
Triglyceride $(>150 \mathrm{mg} / \mathrm{dl})$ & $8 \%)($ & $0(\%)$ & $8(40 \%)$ \\
Cholesterol $(>200 \mathrm{mg} / \mathrm{dl})$ & $2(10 \%)$ & $0(0 \%)$ & $2(10 \%)$ \\
\hline
\end{tabular}




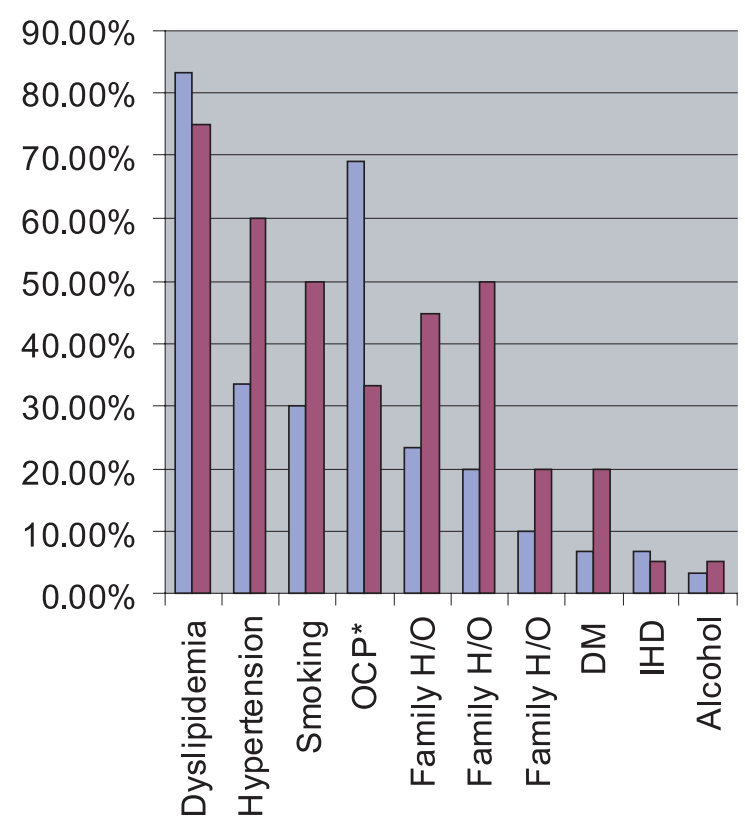

\section{$\square$ Infarction \\ $\square$ Haemorrhage}

Fig.-1: Risk factors associated with stroke

Fig.-1, the bar chart shows different risk factor of infarctive and haemorrhagic stroke in association with percentage of patients involved.

Table-VII

Underlying causes of different types of stroke

\begin{tabular}{llll}
\hline Infarction- & Cardioembolic disease & -4 & $(8 \%)$ \\
& Vasculitis & $-2(4 \%)$ \\
& Undetected & $-24(48 \%)$ \\
& & $-4 \quad(8 \%)$ \\
Intracerebral haemorrhage & Malignant hypertension & -1 & $(2 \%)$ \\
& Anticoagulant drug & -1 & $(2 \%)$ \\
& Eclampsia & $-12(24 \%)$ \\
& Undetected & $-1(2 \%)$ \\
& Arteriovenous malformation & $-1(2 \%)$ \\
\hline
\end{tabular}

Table-VII describes different aetiological variation of types of stroke. Maximum underlying causes failed to detect.

Table-VIII

Short term outcome of different types of stroke

\begin{tabular}{lccc}
\hline Stroke & Improved & Expired & Mortality \\
\hline Infarction & 30 & 0 & $0 \%$ \\
Intracerebral haemorrhage & 13 & 5 & $27.8 \%$ \\
Subarachnoid haemorrhage & 1 & 1 & $50 \%$ \\
\hline Total & 44 & 6 & $12 \%$ \\
\hline
\end{tabular}

Table-VIII shows outcome of patients at the time of discharge. Morbidity rate is significant (50\%) in subarachnoid haemorrhage. 


\section{Discussion:}

Though stroke in young adults was thought to be relatively uncommon previously, recent studies indicating that incidence is not that uncommon ${ }^{5}$. In our study, we considered 15 to 45 years as young and most of the patients were within 31 to 45 years of age. Gender variation was not very much significant with slight male predominance and consistent with other studies ${ }^{5,6}$. Though it is observed in many studies that haemorrhages are the more common than infarction in young age ${ }^{6}, 60 \%$ strokes are infarctive in our study population and only $4 \%$ of strokes are due to subarachnoid haemorrhage which varies from other studies ${ }^{6}$. Among the associated risk factors in infarctive stroke cases, dyslipidemia is present in $83.3 \%$ cases. Other mostly associated risk factors are hypertension, smoking, OCP, family history of stroke. In haemorrhagic cases, dyslipidemia is again found to be the highest associated risk factor present in $75 \%$ cases. Other frequent factors are hypertension, family history of hypertension, smoking, family history of stroke. Diabetes mellitus was not commonly associated risk factor found in our study like other studies. ${ }^{5}$ Alcohol is found to be associated in least cases in both infarctive and haemorrhagic stroke. Hypertension is more frequent in haemorrhagic strokes than Infarctive cases. OCP is more commonly associated with infarction than haemorrhage. Dyslipidemia remains as a silent risk factor regarding both Infarctive and haemorrhagic stroke. In our study we have found that associated lipid abnormality is high LDL in both Infarctive and haomorrhagic strokes present in $73.2 \%$ and $70 \%$ casese respectively. Low HDL is also common in both types $59.9 \%$ and $60 \%$ cases respectively. High cholesterol level is found to be more associated with infarction than haemorrhage. Regarding aetiology, only $8 \%$ are due to cardioembolic disease, which is not so common as compared to other studies ${ }^{5-7}$. However, in some studies, it was found that cardioembolic disease as cause of infarction is less common in developing countries in contrast to atherothrombotic disease which is more common ${ }^{8-10}$. Infarction due to vasculitis is $4 \%$. Malignant hypertension causing intracerebral haemorrhage are $8 \%$. Anti coagulant drugs, eclampsia causing intra cerebral haemorrhage in $2 \%$ cases each. Arteriovenous malformation was responsible for subarachnoid haemorrhage in 1 patient. In $74 \%$ cases $(48 \%$ Infarctive, $24 \%$ intracrebral haemorrhage and $2 \%$ subarachnoid haemorrhage) aetiology could not be identified. It is a matter of debate whether these can be termed as cryptogenic as we could not do angiogram, transoesophageal echocardiogram or other extensive invasive investigations due to unavailability and unaffordibility. However as dyslipidemia is highly prevalent as associated risk factor, it is likely that premature atherosclerosis may consists a considerable proportion of aetiology of young stroke. In-patientl outcome of Infarctive cases in our study population is excellent but of haemorrhagic cases in-patient mortality is higher. Overall mortality is consistant with other studies.

\section{Conclusion:}

Among all stroke, young strokes cast a significant proprtion. To find out the aetiology is of paramount importance to prevent new cases and reccurence. Premature atherosclerotic disease may be the silent killer. Conventional investigations may not identify the causes in many cases. Extensive laboratory work up to be needed to find out the causes in this group. However, stroke in young adults has a serious impact on the victim's family and the society as well. For a precise evaluation of this problem, large scale studies are of crying need as long term prognosis is likely to be better than older adults if treated properly.

\section{Limitations:}

Small study population, unavailability and unaffordability of necessary extensive invasive investigations are limitations of our study. Moreover, interpretations regarding association of risk factors need case control study.

\section{References:}

1. Bonita R, Mendis S, Trusen T, et al. The global stroke initiative. Lancet Neurol 2004;3:391-3.

2. Adams HP Jr, Butler MJ, Biller J, Toffol GJ. Nonhaemorrhagic cerebral infarction in young adults. Arch Neurol 1986;43:793-6.

3. Grundel AB, Cohen RJ, Saul RF, Taylor JR. Cerebral infarction in young adults. Stroke 1978;9:39-42.

4. Toffol GH, Biller J, Adams HP. Nontraumatic intracerebral haemorrhage in young adults. Arch Neurol 1987;44:483-5. 
JM Vol. 9, No. 1

5. Nedeltchev K, der Maur TA, Georgeadis D et al. Ischaemic strokes in young adults: predictors of outcome and recurrence. J Neurol Neurosurg Psychiatry 2005; 76: 191-5.

6. Bevan H, Sharma K, Bradley W. Stroke in young adults. Stroke 1990; 21: 382-6.

7. Lipska K, Sylaja PN, Sarma PS et al. Risk factors for acute iscaemic stroke in young adults in South India. J Neurol Neurosurg Psychiatry 2007; 78: 95963.
8. Nayak SD, Nair M, Radhakrishnan K, et al. Ischaemic stroke in the young adult: clinical features, risk factors and outcome. Natl Med J India 1997; 10: 107-12.

9. Lee T-S, Hsu W-C, Chen C-J, et al. Etiologic study of young ischemic stroke in Taiwan. Stroke 2002; 33: $1950-5$.

10. Garbusinski JM, van der Sande MAB, Bartholome EJ, et al. Stroke presentation and outcome in developing countries. Stroke 2005; 36: 1388-93. 